\title{
Low-dose ionizing radiation increases the mortality risk of solid cancers in nuclear industry workers: A meta-analysis
}

\author{
SHU-GEN QU ${ }^{1 *}$, JIN GAO $^{1 *}$, BO TANG ${ }^{1}$, BO YU ${ }^{1}$, YUE-PING SHEN ${ }^{2}$ and YU TU ${ }^{1}$ \\ ${ }^{1}$ Department of Radiation Health, Research Center of Radiation Protection and Nuclear Safety, \\ School of Radiation Medicine and Protection; ${ }^{2}$ Department of Health Statistics, School of Public Health, \\ Medical College of Soochow University, Suzhou, Jiangsu 215123, P.R. China
}

Received November 27, 2017; Accepted February 28, 2018

DOI: $10.3892 / \mathrm{mco} .2018 .1590$

\begin{abstract}
Low-dose ionizing radiation (LDIR) may increase the mortality of solid cancers in nuclear industry workers, but only few individual cohort studies exist, and the available reports have low statistical power. The aim of the present study was to focus on solid cancer mortality risk from LDIR in the nuclear industry using standard mortality ratios (SMRs) and 95\% confidence intervals. A systematic literature search through the PubMed and Embase databases identified 27 studies relevant to this meta-analysis. There was statistical significance for total, solid and lung cancers, with meta-SMR values of $0.88,0.80$, and 0.89 , respectively. There was evidence of stochastic effects by IR, but more definitive conclusions require additional analyses using standardized protocols to determine whether LDIR increases the risk of solid cancer-related mortality.
\end{abstract}

\section{Introduction}

Adverse health effects due to exposure to ionizing radiation (IR) have been reported since the first application of X-rays. Stochastic effects, primarily the carcinogenic effects of IR exposure, first became known from the Life Span Study of atomic bomb survivors in Japan (1). In contrast to the high-dose

Correspondence to: Professor Yu Tu, Department of Radiation Health, Research Center of Radiation Protection and Nuclear Safety, School of Radiation Medicine and Protection, Medical College of Soochow University, 199 Ren-Ai Road, Suzhou Industrial Park, Suzhou, Jiangsu 215123, P.R. China

E-mail: tuyu@suda.edu.cn

Professor Yue-Ping Shen, Department of Health Statistics, School of Public Health, Medical College of Soochow University, 199 Ren-Ai Road, Suzhou Industrial Park, Suzhou, Jiangsu 215123, P.R. China

E-mail: shenyueping@suda.edu.cn

*Contributed equally

Key words: solid cancer, mortality, low-dose ionizing radiation, nuclear industry, meta-analysis or high-dose-rate IR only seen in Japanese atomic bomb survivors (2) and nuclear accidents, such as Chernobyl (3), nuclear industry and medical workers are nominally only exposed to low-dose or low-dose-rate IR. A large, international cohort study strongly supported that long-term exposure to low-dose IR (LDIR) increases the risk of leukemia, although the increase is only minuscule (4-6). However, recent epidemiological studies highlighted the detrimental effect of persistent exposure to LDIR, and research on nuclear industry workers has demonstrated increased cancer mortality risks following a cumulative dose of $<100 \mathrm{mSv}$ and dose rates of $<10 \mathrm{mSv}$ per year (7), particularly in solid cancers, by the linear non-threshold model (8). As the extensive use of IR in the medical industry, including radiodiagnosis and radiotherapy, is justified and has been well-studied, the aim of the present study was to focus on the health effects of occupational and environmental IR exposure in the nuclear industry.

Mining, historically the primary source of occupational and environmental health risk exposure, was the only means of obtaining natural radionuclides of uranium. As is well known, $\mathrm{U}-238$ comprises $>99 \%$ of uranium ore, and radioactive U-235 comprises only $0.71 \%$ in nature. Uranium mining constituted an internal radiation exposure risk in nuclear industrial workers when they inhaled massive amounts of radon gas and its decay species in mines (9). While there is little information on the association between health risks and internal exposure after inhaling uranium dust (10), the physicochemical properties of uranium are known to present a hazard (11). An international retrospective cohort study demonstrated that uranium workers exhibited a higher solid cancer mortality risk compared with control populations living near nuclear facilities (12-14). In fact, uranium workers were put at significant risk, not only by the $\alpha$-particles of radioactive uranium decay, but also by $\gamma$-ray exposure in the mines.

Radioepidemiology studies in nuclear industry workers confirmed that external exposure to $\gamma$-rays and X-rays in medical care settings increased the health risks of partial solid cancers $(15,16)$. The effect on health care workers was a source of bias in occupational epidemiological studies and was recorded (17-19). The risk was not statistically significant in terms of excess relative risk (ERR) and/or standard mortality ratio (SMR), but there was evidence of increasing cancer mortality risk from exposure to IR $(20,21)$. A number 
of complex factors affect the health of nuclear industry workers, their external exposure to radiation and death of the residents $(20,22)$. There are important statistical limitations in recent epidemiological studies, including the number of subjects in those cohorts, the follow-up period, the mode of adjustment and the differences in statistical methods. Therefore, the challenge was to increase the number of international cohort studies in order to improve the ability to assess health risk and to monitor the long-term follow-up evaluations of nuclear industry workers.

The present study utilized a systematic review of the literature related to the mortality risk of solid cancers, including cancers of the lung, brain and central nervous system (CNS), liver, stomach, colorectum, kidney, bladder and prostate, affecting nuclear industry workers in uranium mining, refining, enrichment and gaseous diffusion plants. The primary aims of this meta-analysis were to determine whether LDIR increases the mortality risk of solid cancers in nuclear industry workers, to determine whether there is a standard mortality risk value among any of the solid cancers from LDIR, and whether the cancer mortality risks exhibited a trend for variation from the classical epidemiological studies.

\section{Data collection methods}

Search strategy. Two electronic search strategies were performed through the PubMed and Embase databases using key words for all fields of 'solid cancer' OR 'lung cancer' OR 'brain cancer' OR 'central nervous system cancer' OR 'liver cancer' OR 'stomach cancer' OR 'colorectal cancer' OR 'colon cancer' OR 'intestinal cancer' OR 'rectum cancer' OR 'kidney cancer' OR 'bladder cancer' OR 'prostate cancer' AND 'mortality' AND 'nuclear industry' OR 'nuclear facility'. The search was limited to journal articles published between January 1, 2000 and December 31, 2016, and there were no language restrictions. The bibliographies of all articles included for data extraction were searched independently for further eligible articles by two authors (S-GQ and JG).

Data selection. The present meta-analysis included original research evaluating subjects working in the nuclear industry with a main occupation in mining, refining, enrichment, non-destructive testing and nuclear weapon research, but not in nuclear power plants, medical facilities, education or nuclear accidents. Atomic bomb survivors were also excluded. LDIR was limited to whole-body IR exposure, with a cumulative mean dose of $<0.5 \mathrm{~Sv}$ per year, or at a low dose rate ( $<10 \mathrm{mSv} /$ day) (23). Only studies published in English were considered for inclusion.

The quality of this systematic review was assessed by detailed selection of participants and by comparison of the results. The data in this study included cohort workers, follow-up period, number of deaths caused by cancers of particular interest to the present study, SMR and $95 \%$ confidence interval (CI). Data were excluded for all reviews, books and reports where workers were engaged in their activities for $<1$ year, and from all articles containing insufficient/incomplete data. Three articles were excluded, although they involved uranium workers and nuclear power $(20,24)$ and uranium gaseous diffusion plants $(25)$, as the radiation doses were closely controlled and were within the range considered as safe. Three articles on the Oak Ridge National Laboratory staff $(26,27)$ and nuclear test participants (28) were also excluded. The data selection was confirmed by carefully reading the full text and supplementary information for each article. In the identified studies, disease was observed and graded according to the International Classification of Diseases, revisions 9/10, and the disease categories were carefully examined. Small intestinal, colon and rectum cancer cases were combined under 'colorectal cancer' in this meta-analysis, as the number of those cancers was small (29).

Statistical analysis. The SMR and 95\% CI were used to evaluate the outcome of the cohort and as measures of solid cancer mortality. If the SMR and 95\% CI were not available for meta-analysis, cohort outcome and mortality were calculated by comparing the number of reported deaths against the expected number of deaths in each group. If the results were published for a single type of cancer, a combined value was computed via analysis of the single sample value. The SMR and 95\% CI were unified in analysis, although reports using $90 \%$ CI were also common for meta-analyses of disease outcomes for the cancers of interest.

Forest plots were used to visually assess the pooled estimates and corresponding 95\% CIs. Homogeneity across studies was tested using Cochran's $\mathrm{Q}$ test at $\mathrm{P}<0.1$, and quantified using the $\mathrm{I}^{2}$ statistics, which represents the percentage of heterogeneity that may be attributed to the variation across studies. In the presence of significant heterogeneity, a random-effects model was applied. We further performed a sensitivity analysis to investigate the influence of a single study on the overall risk estimate by omitting one study in each iteration. The presence of publication bias was assessed using the Begg's and Egger's tests and by examining funnel plots. Two-tailed $\mathrm{P}<0.05$ was considered statistically significant. All the data were analyzed using STATA software, version 11.0 (Stata Corp LP, College Station, TX, USA).

\section{Results}

Selected articles. In the initial search, 547 relevant articles were identified. Of these, 66 were excluded as duplicates, 368 were excluded after reviewing their titles and abstracts, 24 were excluded as reviews, and 62 were excluded as they fell outside the dates of interest of the present study. Following the review, 27 articles $(15,17,26-50)$ were finally selected for the present meta-analysis. The study selection process is summarized in Fig. 1.

Description of studies. The characteristics of the 27 articles included in the present meta-analysis are detailed in Table I. The articles were all retrospective cohorts and the majority were published after 2010. Of the articles included in this study, 1 was performed in Asia, 2 in Australia, 10 in North America and 14 in Europe. Not all the studies included data on all eight types of solid cancers of interest in the present analysis plus the total cancers. Such was the case for the article published by Drubay et al (30), which only included information on kidney cancer and its SMR and 95\% CI. 


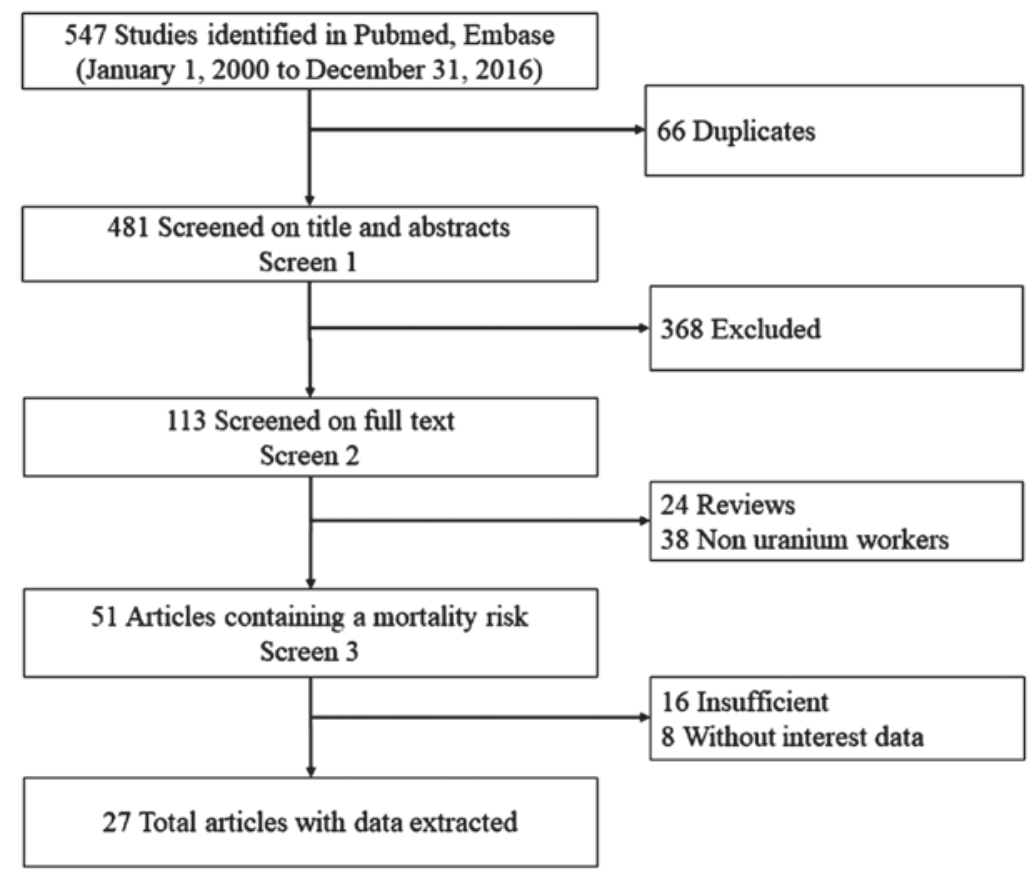

Figure 1. Flow chart of literature search and study selection.

Solid cancer analysis. Only 6 of the 27 studies reported SMR for the solid cancers of interest. The meta-SMR $(95 \% \mathrm{CI})$ of solid cancers in nuclear industry workers was 0.80 (0.71-0.90) after a meta-analysis using the random-effects model (Fig. 2). The fixed-effects model yielded a meta-SMR $(95 \% \mathrm{CI})$ of 0.85 (0.84-0.87), as shown in Table II. There was significant heterogeneity across the 6 studies $\left(\mathrm{I}^{2}=94.6 \%, \mathrm{P}=0.00\right)$. These results indicated that LDIR did not significantly increase solid cancer mortality risk.

Analysis of other tumors. The meta-analysis results of the SMR and 95\% CI for the 8 solid cancers of interest in this study are shown in Table II. The combined SMR was lower compared with that for total cancer $(0.87)$, solid cancer $(0.85)$, lung (0.89), liver (0.73) and stomach cancer (0.85) compared with the general population, and the homogeneity for colorectal cancer, bladder cancer and prostate cancer was unsatisfactory using the random-effects model after the meta-analysis. The heterogeneity analysis revealed significance of the SMR of total cancer, solid cancer, lung, stomach, colorectal cancer, bladder and prostate cancer $(\mathrm{P}<0.1)$, and the $\mathrm{I}^{2}$ value was $<50 \%$ for stomach and prostate cancers. However, the SMRs of the brain and CNS, liver and kidney cancers displayed little heterogeneity in nuclear industry workers $(\mathrm{P}>0.1)$. Furthermore, the $\mathrm{I}^{2}$ value for kidney cancer was $0.00 \%$, with the same results for SMR obtained using the fixed-effects and random-effects models. The forest plots for the SMR of the 8 solid cancers of interest are not shown.

Sensitivity analysis. Sensitivity analysis was conducted to explore potential sources of heterogeneity in the association between solid cancer mortality risk and LDIR, and to determine the influence of various exclusion criteria on the overall risk estimates. No sensitivity analysis was performed for total cancer, solid cancer, or lung cancer as the heterogeneity $\left(\mathrm{I}^{2}\right)$ was $>90 \%$ for these cases. The analysis of brain and CNS cancer produced a meta-SMR $(95 \% \mathrm{CI})$ of 1.16 (1.02-1.31), with the exclusion of the Muirhead et al study, using the fixed-effects model $\left(\mathrm{I}^{2}=0.00 \%, \mathrm{P}=0.02\right)(17)$. Exclusion of the study by Gun et al (28) decreased the SMR for heterogeneity in colorectal cancer $\left(\mathrm{I}^{2}\right)$ to $14.6 \%(\mathrm{P}=0.00)$ and the combined SMR was 0.88 (95\% CI: 0.82-0.94) using the random-effects model. However, in kidney cancer, exclusion of the Rage et al study decreased the P-value to 0.03 with the $\mathrm{I}^{2}$ remaining at $0.00 \%$ (29), and the difference was statistically significant.

Subgroup analysis of the observed SMR was not performed in the present study, as the reviewed studies did not all include grouping in their reports.

Publication bias. No sign of publication bias was observed when the funnel plots were examined, although the heterogeneity of total cancer, solid cancer and lung cancer was relatively high (Table III). The result of Begg's test (continuity corrected) and Egger's test did not indicate evidence of publication bias $(\mathrm{P}>0.1)$.

\section{Discussion}

There has been a rapidly growing interest in the association between LDIR and stochastic effects in nuclear industry workers. It has been demonstrated that LDIR may increase the mortality and morbidity risk of solid cancers, particularly in the lung, brain and CNS, liver and kidney. However, there have been no published pooled studies investigating point-estimate risk of radiation-induced health effects in workers involved in uranium mining, milling, machining and reprocessing. The present study reviewed the available relevant literature to investigate whether exposure to LDIR affects the mortality of solid cancers, and focused on uranium-processing workers, excluding exposure in the medical setting, radiation research, 


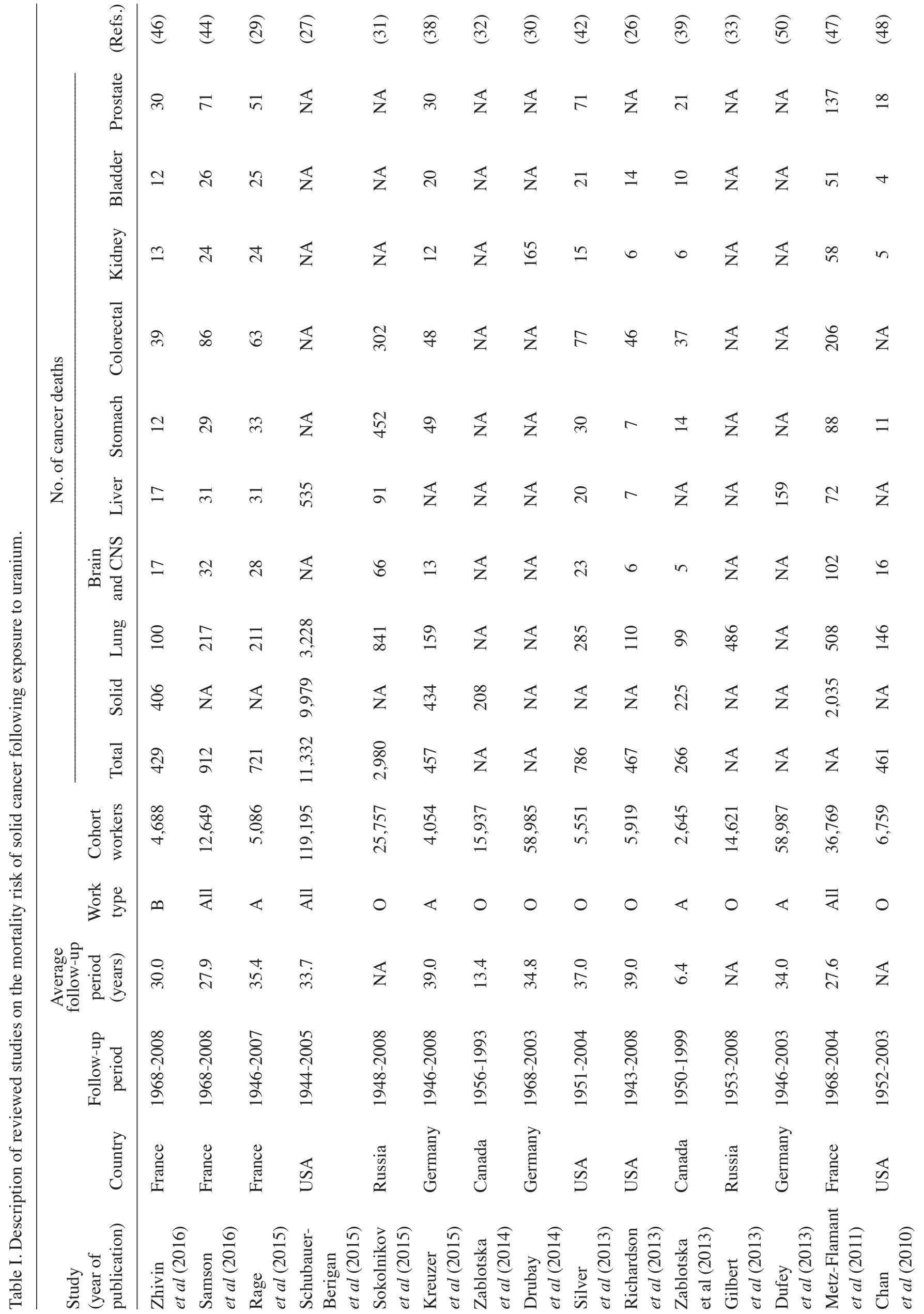




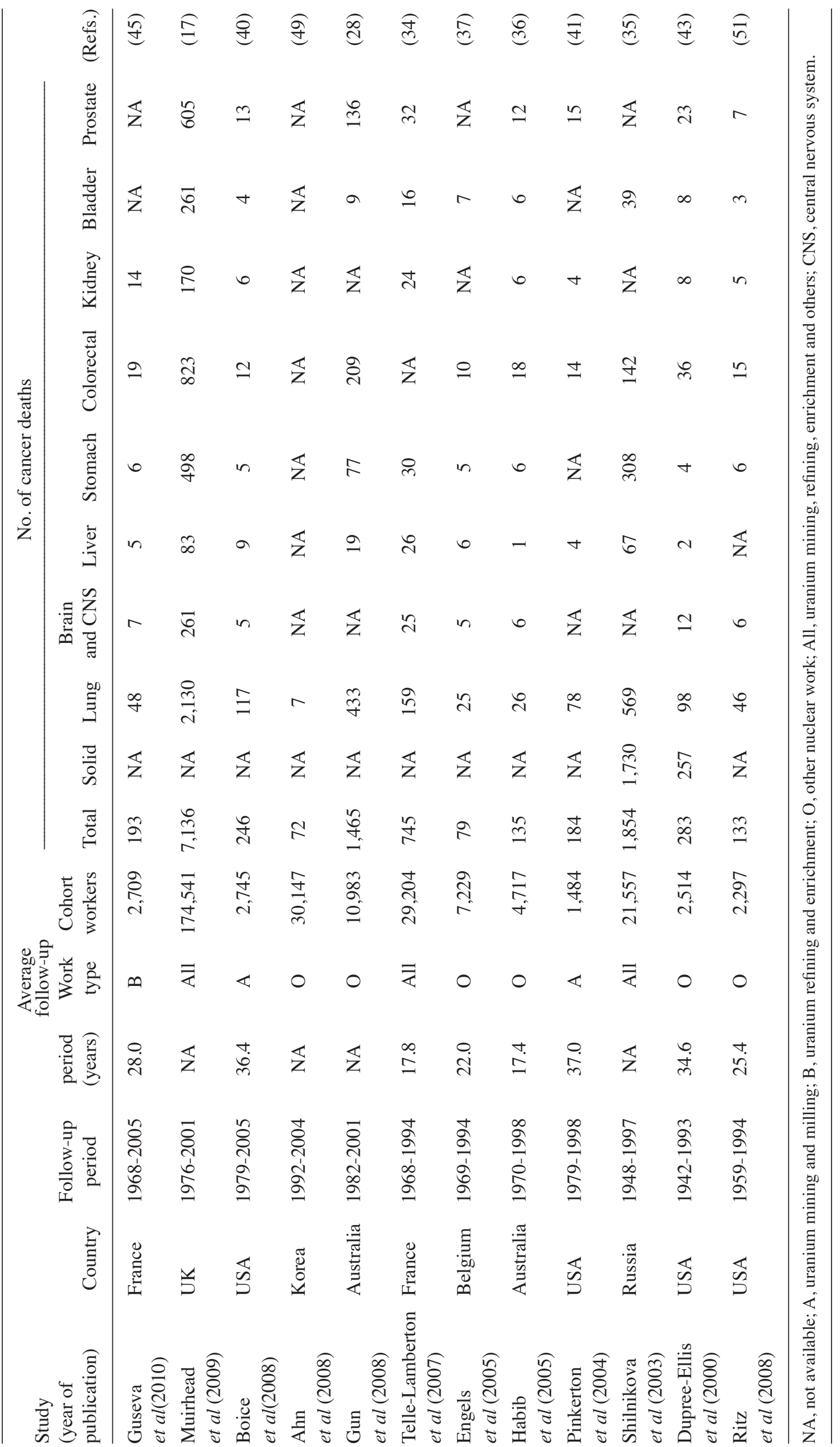




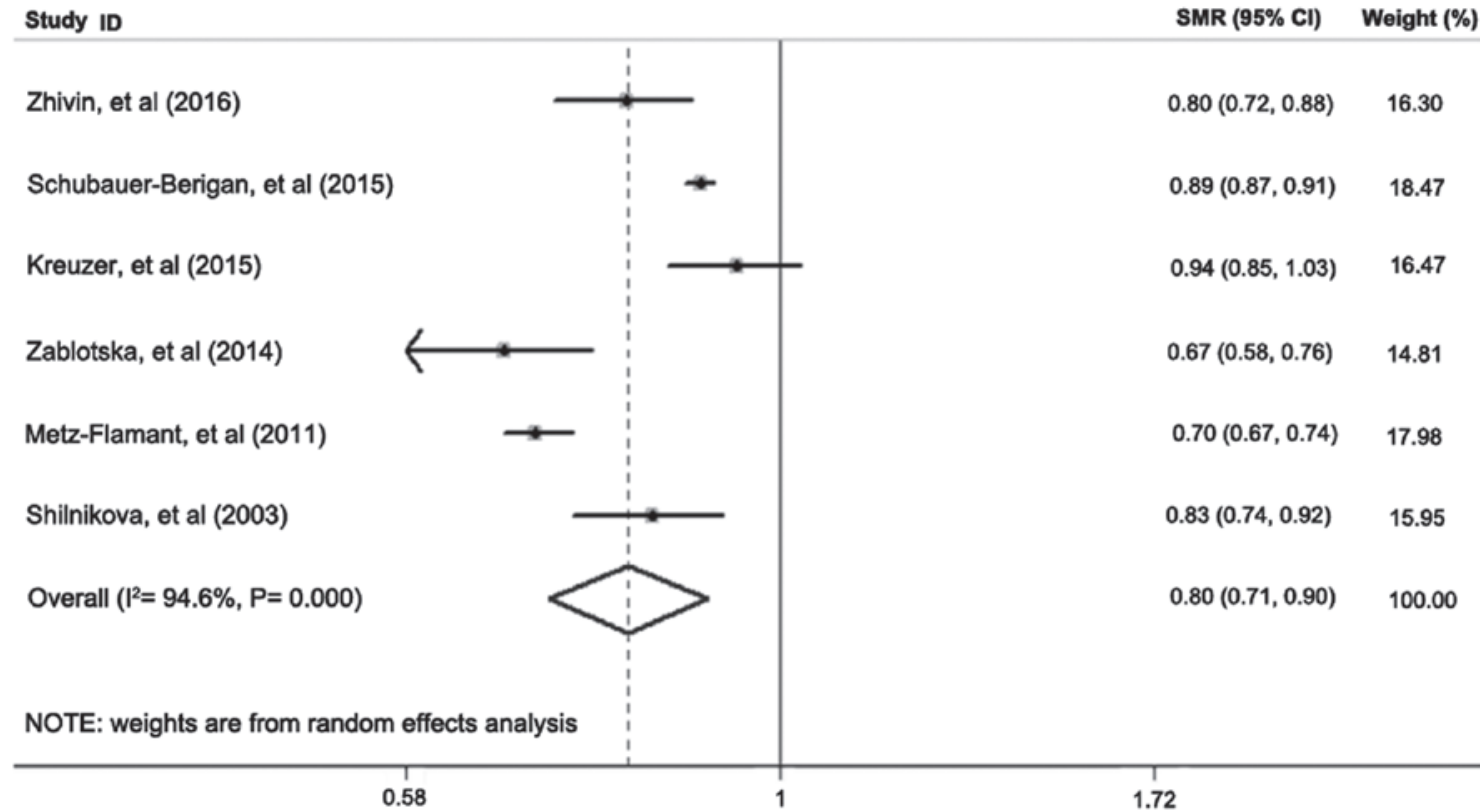

Figure 2. Standard mortality ratio (SMR) and 95\% confidence interval (CI) for solid cancers in reviewed studies on uranium workers.

nuclear weapons manufacturing and nuclear power plant industries.

There are several complicating factors of solid cancer mortality risk in the nuclear industry, such as age at first exposure, mean length of occupational exposure, follow-up period, race, type of occupation, socioeconomic status and lifestyle. Meta-analyses combine multiple articles to highlight the advantages of SMR, while avoiding the limitations inherent in sporadic, single reports. Thus, our meta-analysis of the 27 independent observational studies provided strong evidence that LDIR increases solid cancer mortality risk, compared with control populations, despite the SMR being $<1$. Unfortunately, the large international cohort studies assessed the excess mortality risk of cancer using excess relative risk (ERR) rather than SMR (15,31-33). We found that the high heterogeneity $\left(\mathrm{I}^{2}=94.6 \%, \mathrm{P}=0.00\right)$ in solid cancer mortality risk was attributed to the 6 complete studies, but there was enough evidence to conclude that LDIR could significantly increase brain and CNS cancer mortality risk (combined $\mathrm{SMR}=1.16$; 95\% CI: 1.02-1.31), regardless of whether the fixed-effects or random-effects model was used. Subgroup analysis was not performed, as its over stratification would substantially reduce the subject-pool size, but the result of sensitivity analysis of brain and CNS, colorectal and kidney cancers, it was statistically significant with little heterogeneity $(17,28,29)$. The $90 \%$ CI of SMR was applied in 2 studies $(34,35)$; this value was difficult to convert to 95\% CI for the present meta-analysis, and the calculation of skewed distribution may have reduced the precision. Another source of bias was the combined colorectal SMR in three individual parts of the colon, small intestines and rectum in several studies $(17,26,36-47)$, which could increase heterogeneity. Unfortunately, while the type of work-related exposure may be similar, a large-scale study also has significant differences in sensitivity and may have skewed the results of the meta-analysis.
As the observed populations were not limited only to uranium workers, but included subjects whose primary duties were not mining, such as office administrators, it was quite difficult to determine the effect outcomes of solid cancer mortality resulting from LDIR in the nuclear industry based only on the current studies using non-standard protocols (48). An epidemiological study (11) published in 2014 reported that exposure to the physicochemical properties of uranium could increase the lung cancer mortality risk of nuclear industrial workers, compared with the general population. Similarly, our results demonstrated the relative SMR of lung cancer in uranium-processing workers. There was no statistical significance of SMR for increasing total and solid cancer mortality risk in uranium facility workers when combined with nuclear power plant and medicinal research (49), and the health worker effect was observed. This effect consists of three components, namely the health worker survival (17-19), health worker exposure (52-55) and health worker selection $(55,56)$ effects in occupational exposure epidemiology, and leads to the selection of a working population that is healthier compared with the general population. As a result, the observed SMR of the cancers of interest in this study was lower compared with the control population. Therefore, it is necessary to control the deviation observed in healthcare workers and adjust the sensitivity indicators when comparing the health effects of LDIR exposure of these subjects to uranium-processing workers.

While the absorbed dose of uranium is widely considered as benchmark data to analyze the dose-response association between LDIR and cancer mortality risk, we did not address LDIR dosimetry with ERR in analyzing the influence on uranium workers in this meta-analysis. During the initial study design, it was intended to collect and compare the ERR among the target tumors. In the final study design, however, acquisition and expression of these data and the effect on tumor outcomes was exceedingly difficult and unsatisfactory, as it was also reported by Zhivin et al (11). Dose level, 
Table II. Meta-analysis results on SMR and heterogeneity analysis for solid cancers of interest in nuclear industry workers.

\begin{tabular}{|c|c|c|c|c|c|c|}
\hline \multirow[b]{2}{*}{ Category } & \multicolumn{2}{|c|}{ SMR $(95 \% \mathrm{CI})$} & \multicolumn{4}{|c|}{ Heterogeneity analysis } \\
\hline & Fixed-effects model & Random-effects model & Q-value & $\mathrm{P}$-value & df & $\mathrm{I}^{2}(\%)$ \\
\hline Total cancer & $0.87(0.860 .88)$ & $0.88(0.830 .94)$ & 376.35 & 0.00 & 19 & 95.0 \\
\hline Solid cancer & $0.85(0.840 .87)$ & $0.80(0.710 .90)$ & 92.45 & 0.00 & 5 & 94.6 \\
\hline Lung cancer & $0.89(0.800 .98)$ & $0.89(0.800 .98)$ & 267.25 & 0.00 & 20 & 92.5 \\
\hline Brain and CNS & $1.05(0.961 .14)$ & $1.09(0.981 .21)$ & 18.16 & 0.31 & 16 & 11.9 \\
\hline Liver cancer & $0.73(0.680 .78)$ & $0.75(0.670 .84)$ & 20.18 & 0.17 & 15 & 25.7 \\
\hline Stomach cancer & $0.85(0.800 .91)$ & $0.51(0.750 .97)$ & 33.18 & 0.01 & 17 & 48.8 \\
\hline Colorectal cancer & $0.91(0.870 .95)$ & $0.93(0.841 .04)$ & 45.72 & 0.00 & 16 & 65.0 \\
\hline Kidney & $0.93(0.851 .01)$ & $0.93(0.851 .01)$ & 13.86 & 0.68 & 17 & 0.0 \\
\hline Bladder & $0.87(0.790 .95)$ & $0.96(0.801 .17)$ & 40.48 & 0.00 & 16 & 60.5 \\
\hline Prostate & $1.00(0.941 .06)$ & $0.99(0.911 .08)$ & 23.69 & 0.07 & 15 & 36.7 \\
\hline
\end{tabular}

SMR, standard mortality ratio; CI, confidence interval; df, degree of freedom; CNS, central nervous system.

Table III. Begg's and Egger's tests of the reviewed studies in the metaanalysis of solid cancers of interest from LDIR in the nuclear industry.

\begin{tabular}{lcc}
\hline Cancer category & Begg's test & Egger's test \\
\hline Total cancer & 0.974 & 0.563 \\
Solid & 0.452 & 0.340 \\
Lung & 0.651 & 0.413 \\
Brain and CNS & 0.127 & 0.332 \\
Liver & 0.685 & 0.562 \\
Stomach & 0.820 & 0.657 \\
Colorectal & 0.837 & 0.607 \\
Kidney & 0.596 & 0.446 \\
Bladder & 0.650 & 0.197 \\
Prostate & 0.558 & 0.494 \\
\hline
\end{tabular}

LDIR, lowdose ionizing radiation; CNS, central nervous system.

radiation category, dose monitor standard and particle size associated with LDIR all affect cancer mortality risk, but these factors are often overlooked in basic epidemiological studies. Additionally, classical epidemiological methods rely on risk stratification rather than adjustment for complex factors, and may lead to errors in the analysis of cancer mortality risk.

In the present study, we evaluated the health outcomes due to tumor-related mortality due to LDIR exposure in the uranium industry, despite the fact that the results were complex. As most of the occupational environmental epidemiological findings combined SMR, we did not obtain a positive result. This should be attributed to the collection and analysis of raw data from multiple studies using multiple collection and reporting methodologies. In summary, the results of analytical epidemiological studies lacking statistical efficacy are unsubstantiated. Similarly, the significance of the results gained from a hybrid study that increases statistical performance, but lacks a unified theoretical basis, is also limited.
In summary, the present epidemiological study cannot report definitive findings on the association between LDIR and cancer mortality risk. Based on the available data, a preliminary conclusion could be proffered, using meta-analysis with SMR, that exposure to uranium IR may increase cancer mortality risk, particularly from solid cancers, lung cancer, brain and CNS cancer, colorectal cancer, kidney cancer, bladder cancer and prostate cancer. A convincing and exact outcome could be reached if a more complete study was performed and results that are more precise could be calculated using commonly accepted statistical methods with standardized protocols.

\section{Acknowledgements}

Not applicable.

\section{Funding}

The present study was supported by Chinese Science and Technology Plan Project (no. 2014GB112006), National Natural Science Foundation of China (no. 81372921), The Nuclaer Eneragy Devolopemnt Project (no. 2016-1295) and Postgraduate Research and Practice Innovation Program of Jiangsu Province (KYCX17-2017).

\section{Author contributions}

SGQ and JG performed the meta-analysis and BY performed the data analysis. SGQ, JG and BT participated in writing this paper, YPS and YT designed the study and participated in writing the paper. All authors have read and approved this manuscript.

\section{Availability of data and materials}

The analysed data sets generated during the study are available from the corresponding authors on reasonable request. 


\section{Ethics approval and consent to participate}

Not applicable.

\section{Consent for publication}

Not applicable.

\section{Competing interests}

The authors declare that that they have no competing interests.

\section{References}

1. Ozasa K, Shimizu Y, Suyama A, Kasagi F, Soda M, Grant EJ, Sakata R, Sugiyama H and Kodama K: Studies of the mortality of atomic bomb survivors, Report 14, 1950-2003: An overview of cancer and noncancer diseases. Radiat Res 177: 229-243, 2012.

2. Kamiya K, Ozasa K, Akiba S, Niwa O, Kodama K, Takamura N, Zaharieva EK, Kimura Y and Wakeford R: Long-term effects of radiation exposure on health. Lancet 386: 469-478, 2015

3. Gorsky AI, Maksioutov MA, Tumanov KA, Shchukina NV, Chekin SY and Ivanov VK: Non-parametric analysis of radiation risks of mortality among chernobyl clean-up workers. Radiats Biol Radioecol 56: 138-148, 2016 (In Russian).

4. Abbott A: Researchers pin down risks of low-dose radiation. Nature 523: 17-18, 2015.

5. Leuraud K, Richardson DB, Cardis E, Daniels RD, Gillies M, O'Hagan JA, Hamra GB, Haylock R, Laurier D, Moissonnier M, et al: Ionising radiation and risk of death from leukaemia and lymphoma in radiation-monitored workers (INWORKS): An international cohort study. Lancet Haematol 2: e276-e281, 2015

6. Cardis E, Vrijheid M, Blettner M, Gilbert E, Hakama M, Hill C, Howe G, Kaldor J, Muirhead CR, Schubauer-Berigan M, et al: The 15-country collaborative study of cancer risk among radiation workers in the nuclear industry: Estimates of radiation-related cancer risks. Radiat Res 167: 396-416, 2007.

7. Hall J, Jeggo PA, West C, Gomolka M, Quintens R, Badie C, Laurent O, Aerts A, Anastasov N, Azimzadeh O, et al: Ionizing radiation biomarkers in epidemiological studies-An update. Mutat Res 771: 59-84, 2017.

8. Harbron RW: Cancer risks from low dose exposure to ionising radiation-is the linear no-threshold model still relevant? Radiography 18: 28-33, 2012.

9. Fornalski KW and Dobrzyński L: Pooled Bayesian analysis of twenty-eight studies on radon induced lung cancers. Health Phys 101: 265-273, 2011.

10. Laurier D, Canu IG, Baatout S, Bertho J.-M, Blanchardon E, Bouffler S, Cardis E, Gomolka M, Hall J, Kesminiene A, et al: DoReMi workshop on multidisciplinary approaches to evaluating cancer risks associated with low-dose internal contamination. Radioprotection 47: 119 à 148, 2012.

11. Zhivin S, Laurier D and Guseva Canu I: Health effects of occupational exposure to uranium: Do physicochemical properties matter? Int J Radiat Biol 90: 1104-1113, 2014.

12. López-Abente G, Aragonés N and Pollán M: Solid-tumor mortality in the vicinity of uranium cycle facilities and nuclear power plants in Spain. Environ Health Perspect 109: 721-729, 2001.

13. Krestinina LY, Preston DL, Ostroumova EV, Degteva MO, Ron E, Vyushkova OV, Startsev NV, Kossenko MM and Akleyev AV: Protracted radiation exposure and cancer mortality in the Techa River Cohort. Radiat Res 164: 602-611, 2005.

14. Eidemüller M, Ostroumova E, Krestinina L, Epiphanova S, Akleyev A and Jacob P: Comparison of mortality and incidence solid cancer risk after radiation exposure in the Techa River Cohort. Radiat Environ Biophys 49: 477-490, 2010.

15. Richardson DB, Cardis E, Daniels RD, Gillies M, O'Hagan JA, Hamra GB, Haylock R, Laurier D, Leuraud K, Moissonnier M, et al: Risk of cancer from occupational exposure to ionising radiation: Retrospective cohort study of workers in France, the United Kingdom and the United States (INWORKS). BMJ 351: h5359, 2015.
16. Hunter N, Kuznetsova IS, Labutina EV and Harrison JD: Solid cancer incidence other than lung, liver and bone in Mayak workers: 1948-2004. Br J Cancer 109: 1989-1996, 2013.

17. Muirhead CR, O'Hagan JA, Haylock RG, Phillipson MA, Willcock T, Berridge GL and Zhang W: Mortality and cancer incidence following occupational radiation exposure: Third analysis of the National Registry for Radiation Workers. Br J Cancer 100: 206-212, 2009.

18. Peterson LE and Kovyrshina T: Adjustment of lifetime risks of space radiation-induced cancer by the healthy worker effect and cancer misclassification. Heliyon 1: e00048, 2015.

19. Keil AP, Richardson DB and Troester MA: Healthy worker survivor bias in the Colorado Plateau uranium miners cohort. Am J Epidemiol 181: 762-770, 2015.

20. Metz-Flamant C, Laurent O, Samson E, Caër-Lorho S, Acker A, Hubert D, Richardson DB and Laurier D: Mortality associated with chronic external radiation exposure in the French combined cohort of nuclear workers. Occup Environ Med 70: 630-638, 2013.

21. Bahr DE, Aldrich TE, Seidu D, Brion GM, Tollerud DJ; Paducah Gaseous Diffusion Plant Project Team, Muldoon S, Reinhart N, Youseefagha A and McKinney P Occupational exposure to trichloroethylene and cancer risk for workers at the Paducah Gaseous Diffusion Plant. Int J Occup Med Environ Health 24: 67-77, 2011.

22. Samson E, Telle-Lamberton M, Caër-Lorho S, Bard D, Giraud JM, Metz-Flamant C, Neron MO, Quesne B, Acker A, Tirmarche $\mathrm{M}$ and Hill C: Cancer mortality among two different populations of French nuclear workers. Int Arch Occup Environ Health 84: 627-634, 2011.

23. Little MP, Azizova TV, Bazyka D, Bouffler SD, Cardis E, Chekin S, Chumak VV, Cucinotta FA, de Vathaire F, Hall P, et al: Systematic review and meta-analysis of circulatory disease from exposure to low-level ionizing radiation and estimates of potential population mortality risks. Environ Health Perspect 120: 1503-1511, 2012.

24. Fournier L, Laurent O, Samson E, Caër-Lorho S, Laroche P, Le Guen B, Laurier D and Leuraud K: External radiation dose and cancer mortality among French nuclear workers: Considering potential confounding by internal radiation exposure. Int Arch Occup Environ Health 89: 1183-1191, 2016.

25. Figgs LW: Lung cancer mortality among uranium gaseous diffusion plant workers: A cohort study 1952-2004. Int J Occup Environ Med 4: 128-140, 2013.

26. Richardson DB, Wing S, Keil A and Wolf S: Mortality among workers at Oak Ridge National Laboratory. Am J Ind Med 56: 725-732, 2013.

27. Schubauer-Berigan MK, Daniels RD, Bertke SJ, Tseng CY and Richardson DB: Cancer mortality through 2005 among a Pooled Cohort of U.S. Nuclear Workers Exposed to External Ionizing Radiation. Radiat Res 183: 620-631, 2015.

28. Gun RT, Parsons J, Crouch P, Ryan P and Hiller JE: Mortality and cancer incidence of Australian participants in the British nuclear tests in Australia. Occup Environ Med 65: 843-848, 2008.

29. Rage E, Caër-Lorho S, Drubay D, Ancelet S, Laroche P and Laurier D: Mortality analyses in the updated French cohort of uranium miners (1946-2007). Int Arch Occup Environ Health 88: 717-730, 2015.

30. Drubay D, Ancelet S, Acker A, Kreuzer M, Laurier D and Rage E: Kidney cancer mortality and ionizing radiation among French and German uranium miners. Radiat Environ Biophys 53: 505-513, 2014.

31. Sokolnikov M, Preston D, Gilbert E, Schonfeld S and Koshurnikova N: Radiation Effects on Mortality from Solid Cancers Other than Lung, Liver, and Bone Cancer in the Mayak Worker Cohort: 1948-2008. PLoS ONE 10: e0117784, 2015.

32. Zablotska LB, Lane RSD and Thompson PA: A reanalysis of cancer mortality in Canadian nuclear workers (1956-1994) based on revised exposure and cohort data. Br J Cancer 110: 214-223, 2014.

33. Gilbert ES, Sokolnikov ME, Preston DL, Schonfeld SJ, Schadilov AE, Vasilenko EK and Koshurnikova NA: Lung Cancer Risks from Plutonium: An Updated Analysis of Data from the Mayak Worker Cohort. Radiat Res 179: 332-342, 2013.

34. Telle-Lamberton M, Samson E, Caër S, Bergot D, Bard D, Bermann F, Gélas JM, Giraud JM, HubertP, Metz-Flamant C, et al: External radiation exposure and mortality in a cohort of French nuclear workers. Occup Environ Med 64: 694-700, 2007.

35. Shilnikova NS, Preston DL, Ron E, Gilbert ES, Vassilenko EK, Romanov SA, Kuznetsova IS, Sokolnikov ME, Okatenko PV, Kreslov VV and Koshurnikova NA: Cancer mortality risk among workers at the Mayak nuclear complex. Radiat Res 159: 787-798, 2003. 
36. Habib RR, Abdallah SM, Law M and Kaldor J: Mortality rates among nuclear industry workers at Lucas Heights Science and Technology Centre. Aust N Z J Public Health 29: 229-237, 2005.

37. Engels H, Swaen GM, Slangen J, van Amersvoort L, Holmstock L, Van Mieghem E, Van Regenmortel I and Wambersie A: Radiation exposure and cause specific mortality among nuclear workers in Belgium (1969-1994). Radiat Prot Dosimetry 117: 373-381, 2005.

38. Kreuzer M, Dufey F, Laurier D, Nowak D, Marsh JW, Schnelzer M, Sogl M and Walsh L: Mortality from internal and external radiation exposure in a cohort of male German uranium millers, 1946-2008. Int Arch Occup Environ Health 88: 431-441, 2015.

39. Zablotska LB, Lane RS and Frost SE: Mortality (1950-1999) and cancer incidence (1969-1999) of workers in the Port Hope cohort study exposed to a unique combination of radium, uranium and $\gamma$-ray doses. BMJ Open 3: pii: e002159, 2013.

40. Boice JD Jr, Cohen SS, Mumma MT, Chadda B and Blot WJ: A cohort study of uranium millers and miners of Grants, New Mexico, 1979-2005. J Radiol Prot 28: 303-325, 2008.

41. Pinkerton LE, Bloom TF, Hein MJ and Ward EM: Mortality among a cohort of uranium mill workers: An update. Occup Environ Med 61: 57-64, 2004.

42. Silver SR, Bertke SJ, Hein MJ, Daniels RD, Fleming DA, Anderson JL, Pinney SM, Hornung RW and Tseng CY: Mortality and ionising radiation exposures among workers employed the Fernald Feed Materials Production Center (1951-1985). Occup Environ Med 70: 453-463, 2013.

43. Dupree-Ellis E, Watkins J, Ingle JN and Phillips J: External radiation exposure and mortality in a cohort of uranium processing workers. Am J Epidemiol 152: 91-95, 2000.

44. Samson E, Piot I, Zhivin S, Richardson DB, Laroche P, Serond AP, Laurier D and Laurent O: Cancer and non-cancer mortality among French uranium cycle workers: The TRACY cohort. BMJ Open 6: e010316, 2016.

45. Guseva Canu I, Cardis E, Metz-Flamant C, Caër-Lorho S, Auriol B, Wild P, Laurier D and Tirmarche M: French cohort of the uranium processing workers: Mortality pattern after 30-year follow-up. Int Arch Occup Environ Health 83: 301-308, 2010.

46. Zhivin S, Guseva Canu I, Samson E, Laurent O, Grellier J, Collomb P, Zablotska LB and Laurier D: Mortality (1968-2008) in a French cohort of uranium enrichment workers potentially exposed to rapidly soluble uranium compounds. Occup Environ Med 73: 167-174, 2016.
47. Metz-Flamant C, Samson E, Caër-Lorho S, Acker A and Laurier D: Solid cancer mortality associated with chronic external radiation exposure at the French atomic energy commission and nuclear fuel company. Radiat Res 176: 115-127, 2011.

48. Chan C, Hughes TS, Muldoon S, Aldrich T, Rice C, Hornung R and Tollerud DJ: Mortality Patterns Among Paducah Gaseous Diffusion Plant Workers. J Occup Environ Med 52: 725-732, 2010.

49. Ahn YS, Park RM and Koh DH: Cancer admission and mortality in workers exposed to ionizing radiation in Korea. J Occup Environ Med 50: 791-803, 2008.

50. Dufey F, Walsh L, Sogl M, Tschense A, Schnelzer M and Kreuzer M: Radiation dose dependent risk of liver cancer mortality in the German uranium miners cohort 1946-2003. J Radio Pro 33: 175-185, 2013.

51. Ritz B, Morgenstern H, Crawford-Brown D and Young B: The effects of internal radiation exposure on cancer mortality in nuclear workers at Rocketdyne. Environ Health Perspect 108: 743-751, 2000

52. Greenland S, Fischer HJ and Kheifets L: Methods to explore uncertainty and bias introduced by job exposure matrices. Risk Anal 36: 74-82, 2016.

53. Nielsen MB and Knardahl S: The healthy worker effect: Do health problems predict participation rates in, and the results of, a follow-up survey? Int Arch Occup Environ Health 89: 231-238, 2016.

54. Burstyn I, Lavoué J and Van Tongeren M: Aggregation of exposure level and probability into a single metric in job-exposure matrices creates bias. Ann Occup Hyg 56: 1038-1050, 2012.

55. Punnett L: Adjusting for the healthy worker selection effect in cross-sectional studies. Int J Epidemiol 25: 1068-1076, 1996.

56. Pearce N, Checkoway $\mathrm{H}$ and Kriebel D: Bias in occupational epidemiology studies. Occup Environ Med 64: 562-568, 2007. 